\title{
Harmonic elimination by SPWM and THIPWM techniques applied in photovoltaic inverters
}

\author{
Falil Fatima, Benabadji Noureddine \\ Laboratory for Analysis and Application of Radiation (LAAR), Department of Applied Physics, \\ University USTO Mohamed Boudiaf, Oran, Algeria
}

\begin{tabular}{l}
\hline \hline Article Info \\
\hline Article history: \\
Received Feb 5, 2020 \\
Revised Jan 6, 2021 \\
Accepted Mar 22, 2021 \\
\hline
\end{tabular}

\section{Keywords:}

Inverter, two and three levels Matlab Simulink NPC Structure

PV array SPWM, THIPWM Control

\begin{abstract}
With advances in solid-state power electronic devices, control techniques (PWM) have been devised to obtain high dynamics responses from a multilevel power conditioning converter-Photovoltaic. This work discusses the advantages and drawbacks of two different PWM techniques, the sinusoidal (SPWM) technique and the Third harmonic injection PWM (THIPWM) technique. These two methods are compared by discussing their ease of implementation and by analyzing the output harmonic spectra of various output voltage and their total harmonic distortion (THD). The focus of this paper is the simulation study of single-phase inverter, three phases, two levels and three levels inverter for application photovoltaic. Firstly, single phase is modeled with inductive load and their waveforms are observed. Secondly, a two levels inverter, and three levels inverter are leading to the high industrial performances of the drives synchronous, especially, if a high-power quality is requested.
\end{abstract}

This is an open access article under the CC BY-SA license.

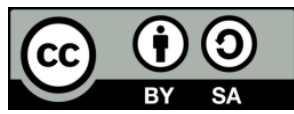

Corresponding Author:

Falil Fatima

Department of Applied Physics, Laboratory for Analysis and Application of Radiation (LAAR)

University Mohamed Boudief (USTO) Mohamed Boudiaf

P.O. Box 1505 El M'naour, Bir-El-Djir, Oran, Algeria

Email: falilfatimaz@yahoo.fr

\section{INTRODUCTION}

The use of static converters in industry has become an extremely broad field, as industrial equipment is using more and more variable speed drives. The major disadvantage of converter is obtaining a nonsinusoidal voltage at its output, which causes a degradation of the operating regime of some loads especially electrical machines. These output voltages are very rich in harmonics, hence the need to reduce them. $[1,2]$. As part of our work, we are dealing with one of the most recommended structures called neutral point clamping (NPC) three-level voltage inverter which will be used to inject electrical energy from a PV source to the distribution network. This topology makes it possible to generate a sinusoidal voltage as much as possible and to improve the harmonic rate thanks to the high number ofits voltage levels offered by the structure of this converter. As part of the search for harmonic reduction methods, several studies have been carried out on two axes. The first is the use of the multilevel topologies of the inverter, while the second deals with the control of the opening and closing of semiconductors forming the inverter (pulse width modulation). In high power applications, the three-level structure is more suitable, compared to the two-level structure, because the voltages and output currents have a much lower harmonic distortion rate.

The use of modulation techniques as a control strategy for the opening and closing of the switches considerably reduces the harmonics. Sinusoidal modulation seems to be the best technique for controlling the opening and closing of Orancontrol of the switches of each arm of the inverter a separate way [3]. The reason why PV arrays are very popular is that it is clean, inexhaustible and requires little maintenance. The 
Photovoltaic systems require interfacing power converters like dc-dc converter and dc-ac inverter between the PV arrays and the grid. And through these grid-connected inverters the generated power from PV system is distributed to power system networks. Solar photovoltaic energy is the fastest growing and promising energy among the types of renewable energy as it is pollution free. The PV arrays in PV system convert solar energy into electrical energy.

Various pulse-width-modulation (PWM) techniques have been developed for industrial applications. For example, PWM-based three-phase voltage source inverters (VSI) convert DC power to AC power with variable voltage magnitude and variable frequency. This thesis discusses the advantages and drawbacks of two different PWM techniques the sinusoidal PWM (SPWM) technique, the third-harmonic-injection PWM (THIPWM) technique. These two methods are compared by discussing their ease of implementation and by analyzing the output harmonic spectra of various output voltages (poles voltages, line-to-neutral voltages, and line-to-line voltages) and their total harmonic distortion (THD). The simulation results show that the THIPWM technique has lower total harmonic distortion than the SPWM technique. The THIPWM technique in the under-modulation region can increase the fundamental output voltage by $15.5 \%$ over the SPWM technique.

The system studied in our work, consists of single-phase and three-phase voltage inverters (two levels and three levels of NPC structure controlled by SPWM with two carriers). To achieve this end, we intend to develop an algorithm for controlling the inverter based on this modulation technique. The operation of this algorithm will be tested on a permanentmagnet synchronous motor. The tests will also concern the impact of using this technique on the reduction of electromagnetic torque ripples. It will also question to determine the harmonic rate (THD) to prove the effectiveness of this algorithm and consequently the efficiency of the PWM technique applied to voltage inverters. The work will present the modeling of the global PV-Boost-Inverters systems (single-phase and three-phase). Firstly, we will treat the single-phase inverter powered inductive load then voltage inverters two levels and three levels powered permanent magnet synchronous machine, as well as we will be devoted to the different control strategies of the inverter, the SPWM and THIRPWM. Finally, we will program and simulate the PWM algorithm applied to inverters under MATLAB/Simulink. The results obtained will be interpreted and discussed.

\section{CONTROL STRATEGIES INVERTERS}

\subsection{Sine pulse width modulation (SPWM)}

SPWM is the easiest modulation method to implement. It is also one of the most limited in terms of achievable voltage amplitude. Because of the modulation, the amplitude of the fundamental is necessarily smaller than the amplitude obtained by full wave control. For the three-phase voltage inverter, the SPWM limits the amplitude of the fundamental to $\mathrm{E}_{\mathrm{dc}} / 2=50.0 \% \mathrm{E}_{\mathrm{dc}}$. In SPWM, a sinusoidal voltage wave called reference is compared to a triangular wave called carrier to generate the control signals of the inverter switches. [4].

\subsubsection{Triangulo-sinusoidal single-carrier modulation}

As for the two-level inverters, the control signals of the switches of the NPC inverter are obtained from the intersections of the three sinusoidal reference signals offset from each other by $120^{\circ}$, of frequency $f_{r}$ and amplitude $U_{r m}$, with a triangular signal of amplitude $U_{p m}$ and frequency $f_{p}$, much greater than $f_{r}[5]$. If the reference is sinusoidal, we define two variables:

- The modulation index defines the ratio between the frequency $\mathrm{f}_{\mathrm{p}}$ and the frequency $\mathrm{f}_{\mathrm{r}} m_{f}=f_{p} / f_{r}$.

- The modulation rate gives the ratio between the amplitude of the modulator $U_{\mathrm{rm}}$ and that of the carrier $\mathrm{U}_{\mathrm{pm}}, \mathrm{IM}=\mathrm{U}_{\mathrm{rm}} / \mathrm{U}_{\mathrm{pm}}$

The principle of this strategy Figure 1 can be summarized by the following algorithm [6]:

$$
U_{r} \geq U_{p} \Rightarrow S_{2}(t)=1 \text { or } S_{2}(t)=0 .
$$

$\mathrm{U}_{\mathrm{r}}$ : Reference voltage $; \mathrm{U}_{\mathrm{p}}$ : Carrier Voltage; $\mathrm{S}_{2}(\mathrm{t})$ signal generated by PWM 


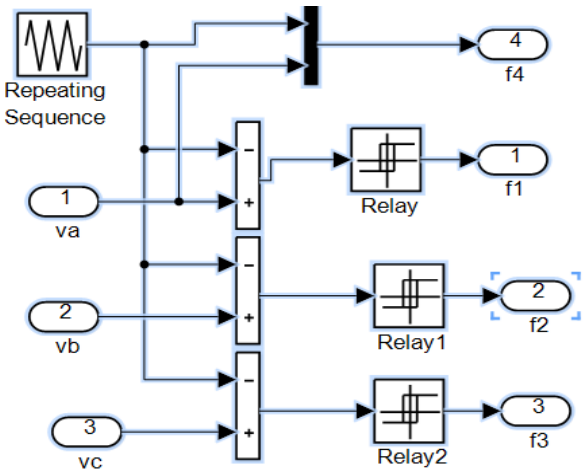

(a)

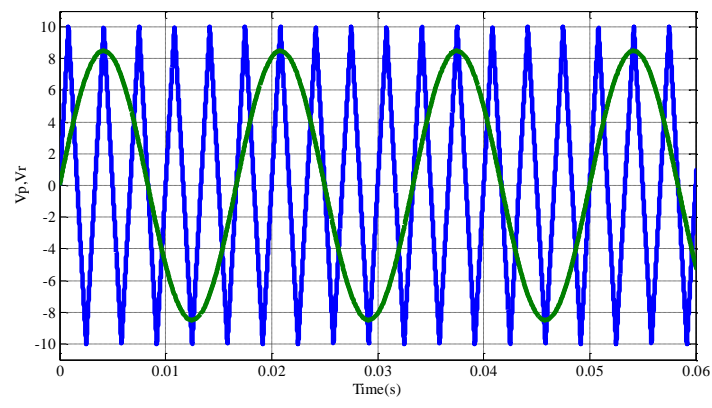

(b)

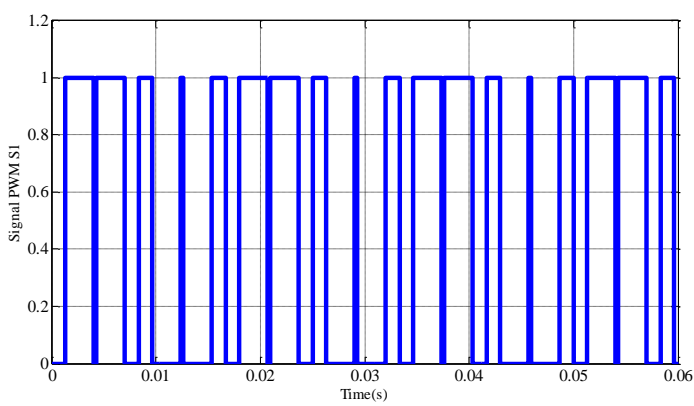

(c)

Figure 1. (a) Model SPWM technique under Matlab (b) Ur and $U_{p}$, (c) signal generated by PWM

\subsubsection{Results and discussion}

Figure 2 show the increase of the fundamental amplitude as a function of modulation rate in a linear way and spectrum of output voltage harmonics $V_{\text {an }}$ shows that there are two kinds of families: the families' even indices and odd indices. We can see in addition that the voltage harmonics are grouped in families centered on the frequencies of odd multiple switching of the fundamental frequency. We conclude that the higher modulation index has a lower THD (\%).

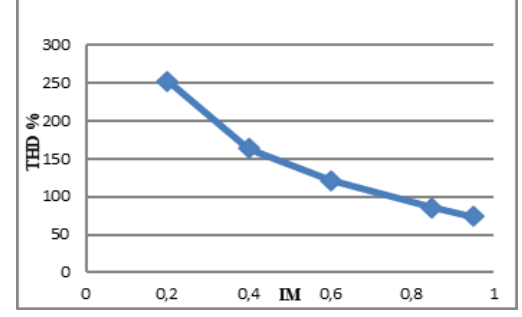

(a)

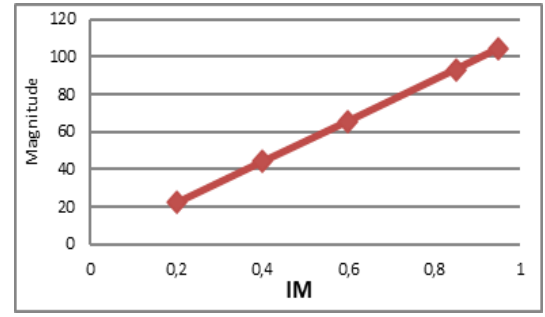

(b)

Figure 2. (a) THD according to IM, (b) Amplitude of fundamental according to IM. For two-level inverter

\subsubsection{Triangular-sinusoidal two-carrier control of the inverter three levels}

Triangular sinusoidal control two carriers use the fact that a three-level inverter is likened to the series connection of two inverters at two levels. It uses two triangular carriers $U_{\mathrm{p} 1}, \mathrm{U}_{\mathrm{p} 2}$ phase shifted from each other by half ofthe period $\mathrm{T}_{\mathrm{p}}$ Hash.

The algorithm for this strategy comes down to the followingtwo steps [7]:

- Step Determination ofintermediate signals $V_{K 1}, V_{K 0}$ 
$\left\{\begin{array}{l}V_{r e f k} \geq U_{p 1} \Rightarrow V_{k 1}=\frac{E}{2} \\ V_{r e f k}<U_{p 1} \Rightarrow V_{k 1}=0\end{array}\right.$ And $\left\{\begin{array}{c}V_{r e f k} \geq U_{p 2} \Rightarrow V_{k 0}=0 \\ V_{r e f k}<U_{p 2} \Rightarrow V_{k 0}=\frac{-E}{2}\end{array}\right.$ Where $E=U_{c}$

- Step Determination of the $\mathrm{V}_{\mathrm{k} 2}$ signal and the $\mathrm{F}_{\mathrm{ks}}$ control commands of the switches [8]

$$
\begin{aligned}
& V_{K 2}=V_{K 0}+V_{K 1} \\
& V_{K 2}=\frac{E}{2} \Rightarrow F_{K 1}=1, F_{K 2}=1 \\
& V_{K 2}=\frac{-E}{2} \Rightarrow F_{K 1}=0, F_{K 2}=0 \\
& V_{K 2}=0 \Rightarrow F_{K 1}=1, F_{K 2}=0
\end{aligned}
$$

The results of this strategy is show in the Figure 3
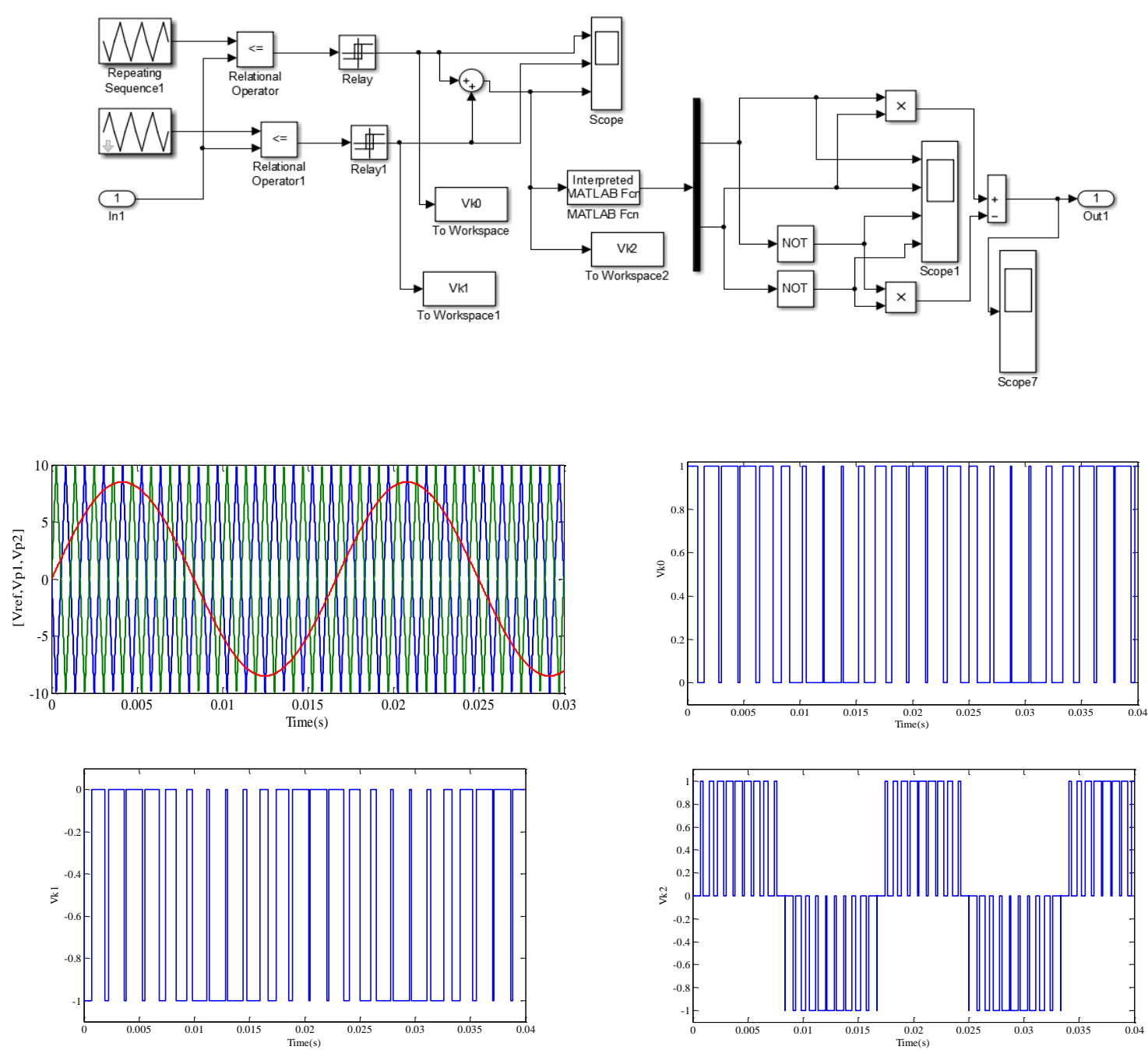

Figure 3. Principle of the two-carrier sinusoidal triangular strategy for $\mathrm{IM}=0.85, \mathrm{~m}_{\mathrm{f}}=10$

\subsubsection{Simulation result and discussioms}

The simulation results show in Figures 4 and 5 that THD is very low for the three-level structure compared to that generated by the two-level inverter. THD is very low for the three-level structure compared to that generated by the two-level inverter. 

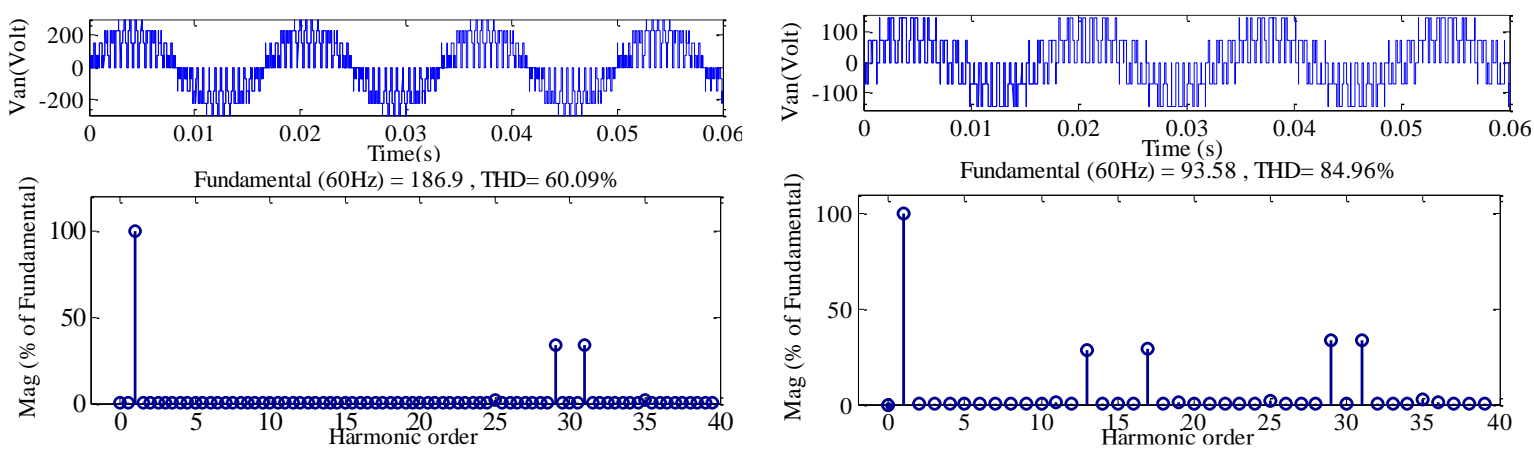

(a)

(b)

Figure 4. (a) $\mathrm{V}_{\text {an }}$ voltage and harmonic spectrum of the three-level inverter controlled by SPWM two carrier,

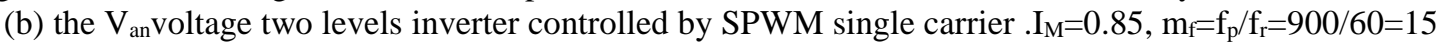
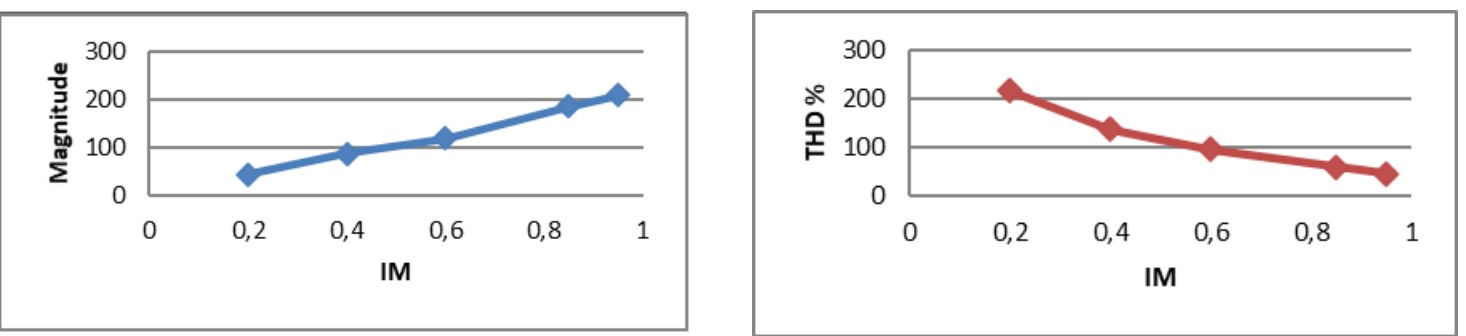

Figure 5. THD and Fundamental amplitude versus IM for three-level inverter controlled by SPWM with two carriers

\subsection{Third-harmonic-injection THIRPWM}

The sinusoidal PWM is the simplest modulation scheme to understand but it is unable to fully utilize the available DC bus supply voltage. Due to this problem, the third-harmonic -injection pulse width modulation (THIPWM) technique was developed to improve the inverter performance [9]. Injection a third harmonic component to the fundamental component gives the following modulating waveforms for the three phases [10]:

$$
\begin{aligned}
& V_{a n}=\frac{2}{\sqrt{3}}\left(\sin (w t)+\frac{1}{6} \sin (3 w t)\right) \\
& V_{b n}=\frac{2}{\sqrt{3}}\left(\sin (w t-2 \pi / 3)+\frac{1}{6} \sin (3 w t)\right) \\
& V_{c n}=\frac{2}{\sqrt{3}}\left(\sin (w t+2 \pi / 3)+\frac{1}{6} \sin (3 w t)\right)
\end{aligned}
$$

We present in Figure 6 one phase third-harmonic injection PWM. The THIPWM is implemented in the same manner as the SPWM, that is, the reference waveforms are compared with a triangular waveform. As a result, the amplitude of the reference wave forms does not exceed the DC supply voltage $\mathrm{V}_{\mathrm{dc}} / 2$, but the fundamental component is higher than the supply voltage $\mathrm{V}_{\mathrm{dc}}$. As mentioned above, this is approximately 15.5\% higher in amplitude than the normal sinusoidal PWM. Consequently, it provides a better utilization of the DC supply voltage [9]. The one reference voltage and triangular waveform of a one phase THIPWM produce the following output pole voltage. $\mathrm{V}_{\text {ao }}$ show in Figure 7. Injection of harmonic of order three in the reference makes it possible to increase the zone of linearity of the fundamental one. 


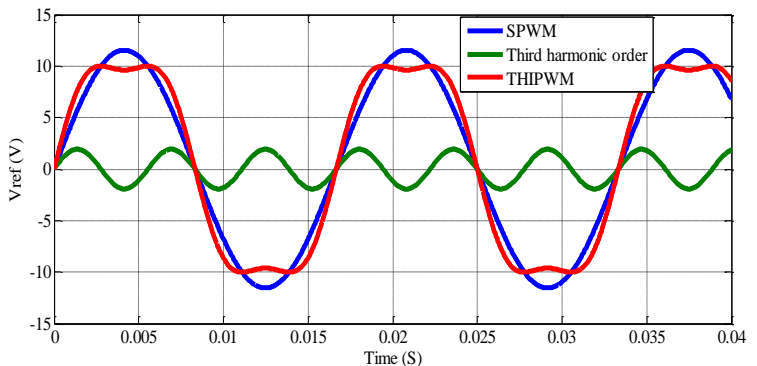

Figure 6. One phase third-harmonic injection PWM

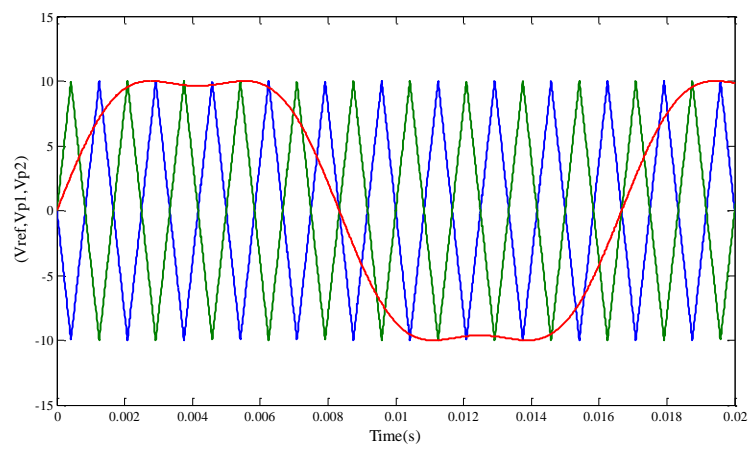

Figure 7. Refrence voltage, Tow triangulair wave forms for $\mathrm{I}_{\mathrm{m}}=\mathrm{U}_{\mathrm{r}} / \mathrm{U}_{\mathrm{p}}=1.15, \mathrm{~m}_{\mathrm{f}}=\mathrm{f}_{\mathrm{p}} / \mathrm{f}_{\mathrm{r}}=10$

\section{SIMULATION AND RESULTS OF SPWM AND THIPWM TECHNIQUES IN MALTLAB}

\subsection{Single phase inverter $P V$ with inductive-resistive load}

After having examined the strategy of the control techniques of the inverter, we carried out the simulation of the PV module-Boost- single phase inverter system controlled by two techniques of control SPWM, THIPWM under environment MATLAB-SIMULINK, taking into account consider the following parameters:

Continuous power source obtained by PV module, the fundamental frequency ( $f=60 \mathrm{~Hz}$ ). The order side comparison is based on the following factors:

- Harmonic spectrum

- $\quad$ Amplitude of fundamentals according to the modulation index

- $\quad$ The harmonic total distortion rate (THD)

To make a comparative study of two orders, we made a series of tests in simulation. We present the simple output voltage of the single-phase inverter, as well as the spectrum of its harmonics for $\mathrm{m}_{\mathrm{f}}=16.66$ $\left(f_{p}=1000, f r=60\right)$ and $I M=0.85$ in the Figure 8.

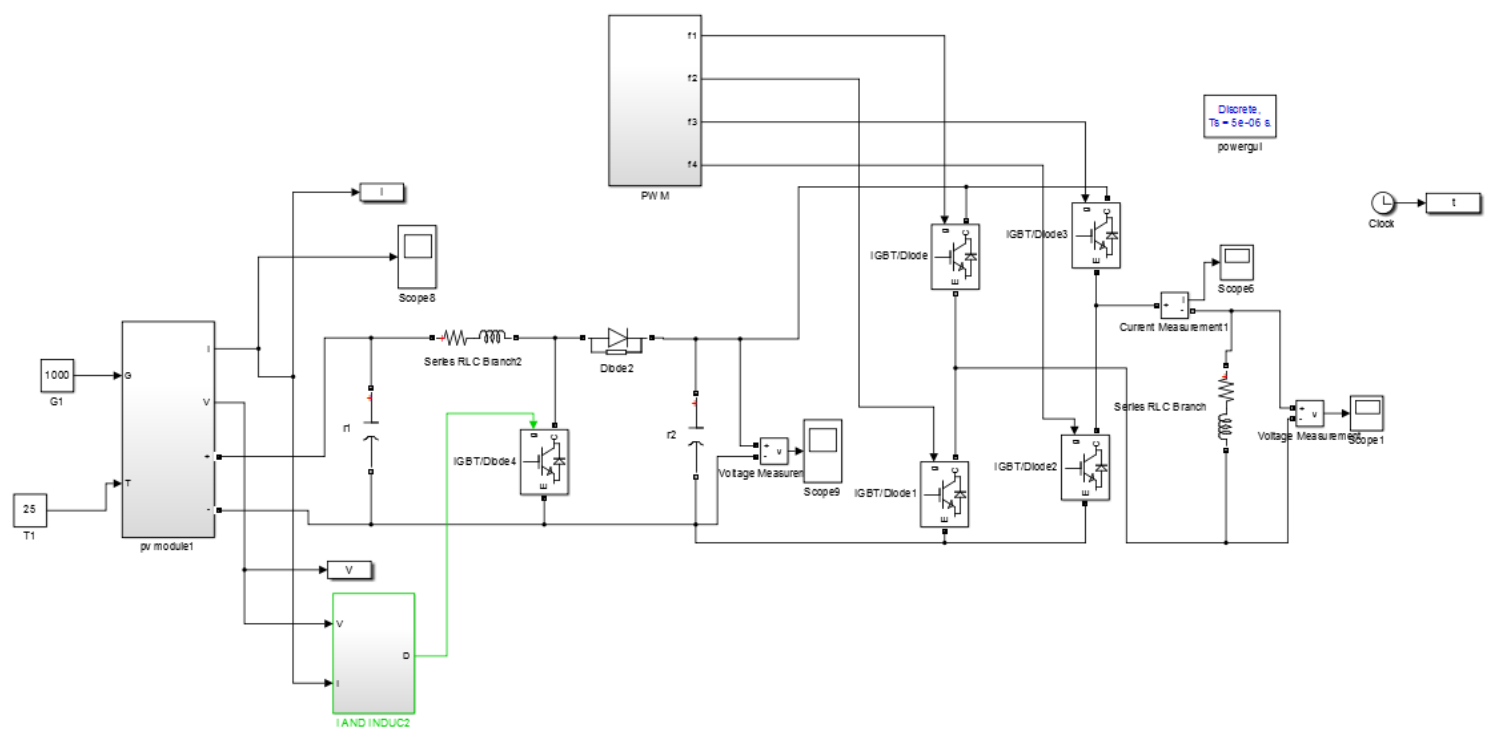

Figure 8. Block diagram of association (PV array-Boost-single phase inverter RL) system under MatlabSimulink

\subsection{System description}

3.2.1. PV array

Open the PV-array block menu and look at model parameters. Specifications for one module: characteristics of a PWX 500 PV module are: 
- Number of series-connected cells: 36

- Open-circuit voltage: $\mathrm{V}_{\mathrm{oc}}=21.8 \mathrm{~V}, \mathrm{~V}_{\mathrm{mp}}=17 \mathrm{~V}$

- Short-circuit current: $\mathrm{Isc}=3.11 \mathrm{~A}, \mathrm{I}_{\mathrm{mp}}=2.88 \mathrm{~A}, \mathrm{P}_{\mathrm{mp}}=49 \mathrm{~W}$.

- The array consists of 8 strings of 5 series-connected modules connected in parallel.

- $\quad \mathrm{N}_{\mathrm{ss}}=5, \mathrm{~N}_{\mathrm{p}}=8$ the value of voltage output is $\mathrm{V}_{\text {module }}=5 * \mathrm{~V}$ and the value of current output is $\mathrm{I}_{\text {module }}=8 * \mathrm{I}$.

The PV array block menu allows you to plot the I-V\&P-V as shown in Figure 9.

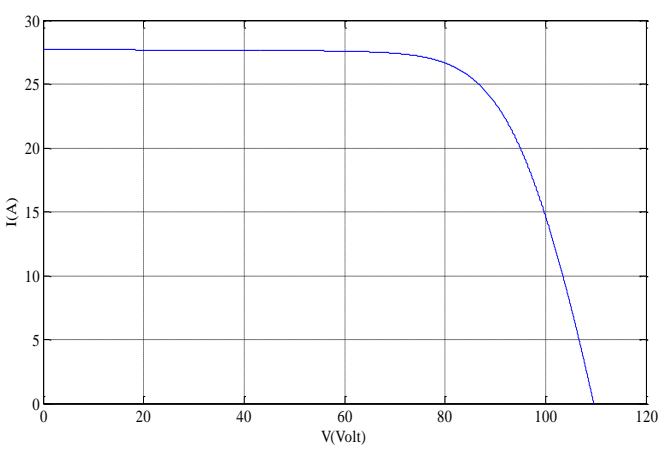

(a)

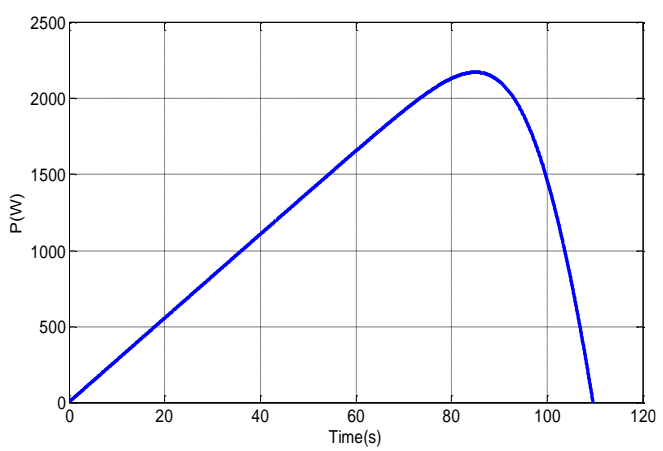

(b)

Figure 9. (a) I-V, (b) P-V characteristics of PV array

\subsubsection{Boost converter}

Figure 8 show model of the boost converter boosts DC voltage from $87 \mathrm{~V}$ to $200 \mathrm{~V}$. This converter uses a MPPT (Incremental Conductance [11, 12]) system which automatically varies the duty cycle in order to generate the required voltage to extract maximum power.

\subsection{Results simulations of single-phase inverter applied with SPWM, THIPWM}

A full-bridge voltage source-inverter with inductive-resistive load can be considered as shown in Figure 8 with representin gload by only resistance and inductance. When $\mathrm{T}_{1}$ and $\mathrm{T}_{2}$ are connected, the input voltage $V_{c}$ appears across the load. If $T 3$ and $T_{4}$ are connected the voltage across the load is $-V_{c}$. Figures 1011 shows simulation circuit by Matlab Simulink and Simple voltage and its harmonic spectrum waveforms with two techniques SPWM and THIPWM. After having examined the two control techniques SPWM and THIPWM of the inverter, we go to the study of the performances of the latter. It can be deduced that the addition of the harmonic three makes it possible to increase the maximum amplitude of the background in the reference and, hence, in the output voltages, therefore the third order harmonics are eliminated and the THD is decrease.
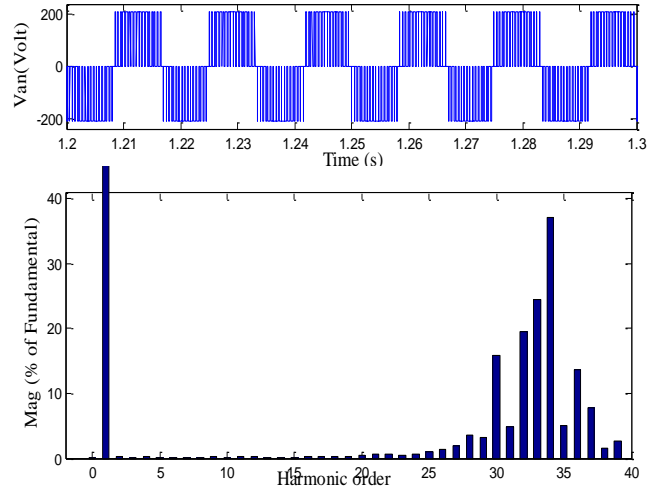

Figure 10. Simple voltage and its harmonic spectrum, $\mathrm{m}_{\mathrm{f}}=16.666, \mathrm{IM}=0.85, \mathrm{THD}=70.43 \%$ fundamental $=180$ volts with SPWM technique
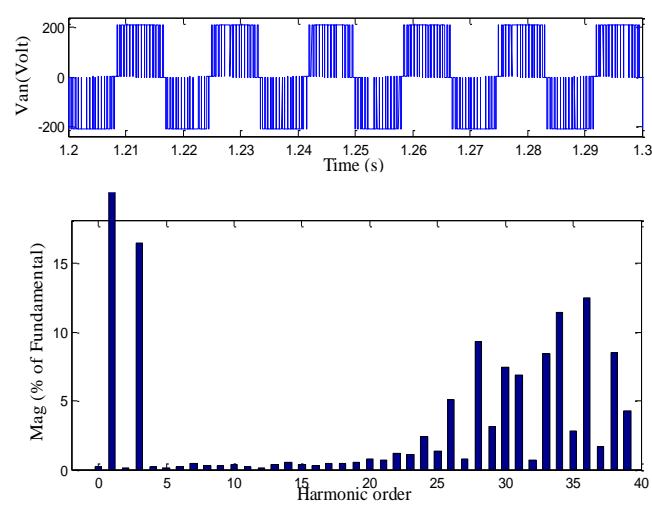

Figure 11. THIPWM technique simple voltage and its harmonic spectrum, $\mathrm{m}_{\mathrm{f}}=16.666, \mathrm{IM}=1.15$, THD $=40.42 \%$ fundamental $=244.2$ volts with THIRPWM technique 


\section{THREE PHASE INVERTER - PV WITH PERMANENT MAGNET SYNCHRONOUS \\ MACHINE}

We performed the simulation of the permanent magnet synchronous machine powered by the two inverter structures (two levels and three levels) controlled by PWM techniques. We realized this work under environment MATLAB / SIMULINK for $\mathrm{m}_{\mathrm{f}}=333.33$ a fundamental frequency $\mathrm{f}_{\mathrm{r}}=60 \mathrm{~Hz}$ and $\mathrm{f}_{\mathrm{p}}=20 \mathrm{khz}$, $\mathrm{Uc}=200 \mathrm{~V}$ Figure 12 . The test is characterized by a vacuum start, then a change of the resisting torque performed at the instant $\mathrm{t}=0.55 \mathrm{~s}$ during simulation. After the model validation shown in Figure 12 under Matlab-Simulink, we reported the results of simulations.

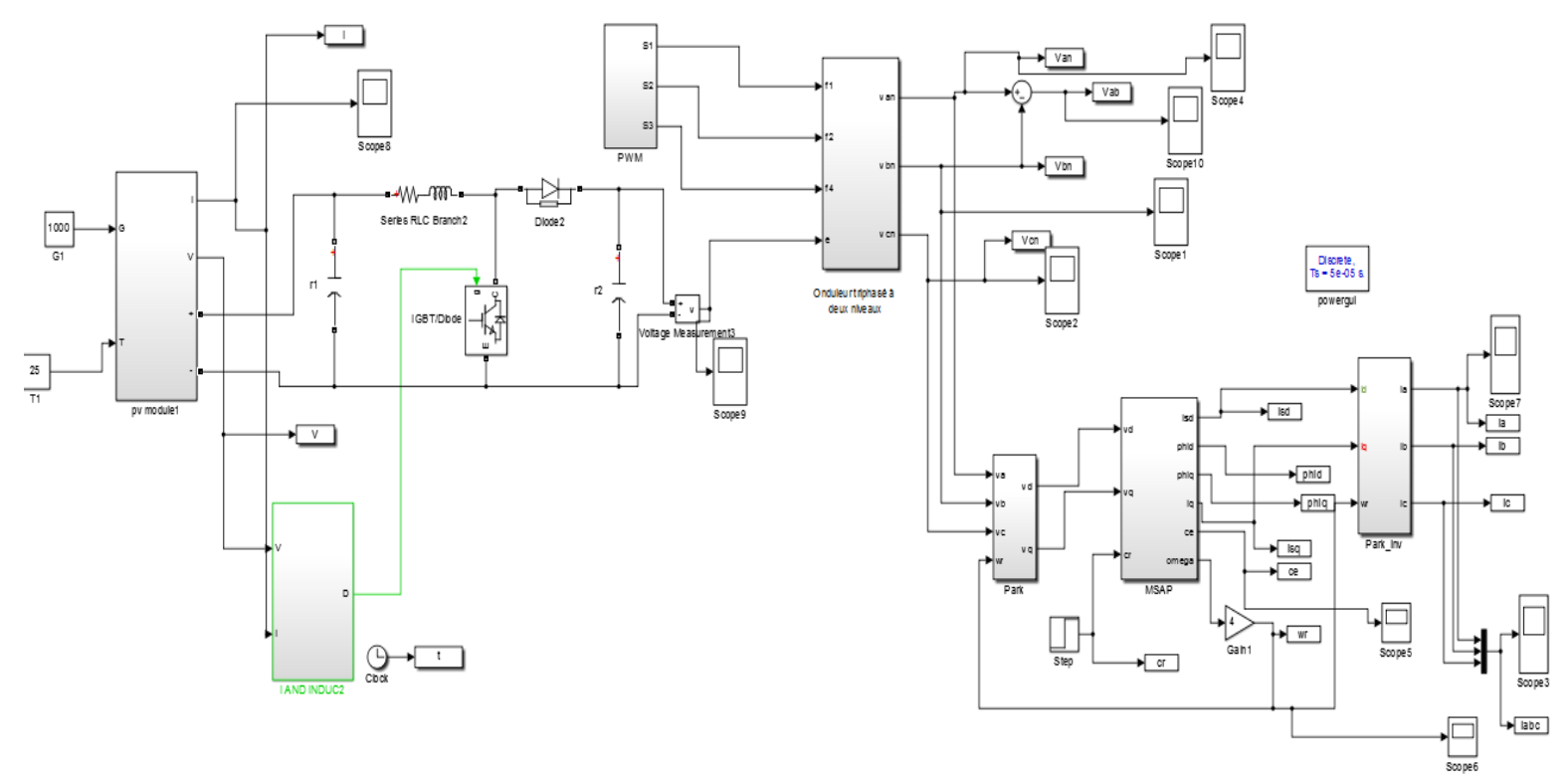

Figure12. Block diagram of association (PV array-Boost -Three phase inverter -permanent magnet synchronous machine) system under Matlab -Simulink

\subsection{Modeling of the two-level inverter}

A three-phase inverter with two levels can be considered as consisting of three half-phase singlephase inverters out of phase with each other by $120^{\circ}$. Power is supplied by a DC voltage source or a voltagecontrolled capacitor as shown in Figure 13. The inverter will be modeled using the notions of connection functions and conversion functions. It should be noted that on an inverter arm the connection functions verify the arithmetic relation.

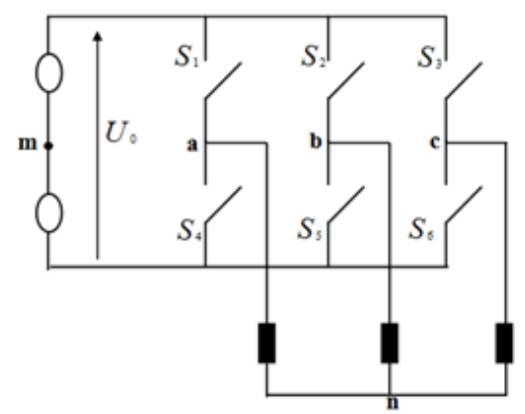

Figure 13. Block diagram of the two-level inverter

a) Connection function

The function of connection of a switch $\mathrm{S}_{\mathrm{j}} \mathrm{F}_{\mathrm{cj}}$ allows to define the state of it: 


$$
\left\{\begin{array}{l}
F_{C J}=1 \text { if } S_{J} \text { is closed } \\
F_{C J}=0 \text { if } S_{J} \text { is open }
\end{array}\right.
$$

b) Conversion function

The converter function of a voltage inverter $\mathrm{m}_{\mathrm{cj}}$ is used to express the output voltage as a function of the input voltage. For a three-phase inverter defined by the following figure, it is possible to define three conversion functions $\mathrm{m}_{\mathrm{ca}}, \mathrm{m}_{\mathrm{cb}}, \mathrm{m}_{\mathrm{cc}}$, such as:

$$
\left\{\begin{array}{l}
V_{a n}=m_{c a} \cdot U_{0} \\
V_{b n}=m_{c b} \cdot U_{0} \\
V_{c n}=m_{c c} \cdot U_{0}
\end{array}\right.
$$

It should be noted that on an inverter arm the connection functions check the arithmetic relation $F_{c j}+F_{c j}=1$ so as not to short circuit the voltage source $\mathrm{U}_{\mathrm{c}}$ and do not open a current source. We deduce the expression of the tensions with respect to the fictitious midpoint (m)

$$
\begin{aligned}
& V_{a m}=\left(f_{c a}-f_{c^{\prime} a}\right) \cdot \frac{U_{0}}{2}=\left(2 f_{c a}-1\right) \frac{U_{0}}{2} \\
& V_{b m}=\left(f_{c b}-f_{c^{\prime} b}\right) \cdot \frac{U_{0}}{2}=\left(2 f_{c b}-1\right) \frac{U_{0}}{2} \\
& V_{c m}=\left(f_{c c}-f_{c^{\prime} c}\right) \cdot \frac{U_{0}}{2}=\left(2 f_{c c}-1\right) \frac{U_{0}}{2}
\end{aligned}
$$

Since the load is supposed to be balanced in the absence of a zero-sequence voltage component, the sum of the simple voltages is zero, this makes it possible to write:

$$
\begin{aligned}
& V_{a n}+V_{b n}+V_{c n}=0 \\
& \Rightarrow V_{m n}=-\frac{1}{3}\left(V_{a m}+V_{b m}+V_{c m}\right)
\end{aligned}
$$

We finally get

$V_{m n}=\frac{U_{0}}{2}-\left(f_{c a}+f_{c b}+f_{c c}\right) \cdot \frac{U_{0}}{3}$

Knowing that

$$
\begin{aligned}
& V_{a n}=V_{a m}+V_{m n} \\
& V_{a n}=\frac{U_{0}}{3}\left(2 f_{c a}-f_{c b}-f_{c c}\right)
\end{aligned}
$$

Finally, We obtain, by analogy for $V_{b n}, V_{c n}$

$$
\left\{\begin{array}{l}
V_{a n}=\frac{U_{0}}{3}\left(2 f_{c a}-f_{c b}-f_{c c}\right) \\
V_{c n}=\frac{U_{0}}{3}\left(-f_{c a}+2 f_{c b}-f_{c c}\right) \\
V_{c n}=\frac{U_{0}}{3}\left(-f_{c a}-f_{c b}+2 f_{c c}\right)
\end{array}\right.
$$

\subsection{Total distortion of THD voltage harmonics}

An important factor in assessing the performance of the PWM is the total distortion factor of the output voltage harmonics (THD), defined by the ratio of the quadratic sum of the voltage harmonics to the fundamental value of the voltage [8]. 


$$
T H D=\frac{1}{V_{1}}\left[\sum_{n=2.3}^{n} V_{n}^{2}\right]
$$

\subsection{Operation Three level inverter}

\subsubsection{Structure of the inverter}

The structure chosen in this study is that of the NPC three-phase voltage inverter. Several studies are done on two-level inverters, both from the point of view of modeling and control strategy. We will try specially to deepen the parts concerning the multilevel inverters. And several structures are possible for the inverter with three levels. We choose to study the NPC structure [13], this inverter is said to three levels because it delivers three voltage levels $\left(+U_{c}, 0,-U_{c}\right)$. This structure is presented in the Figure 14:

\subsubsection{Three-level inverter control control model}

In a single phase (an inverter arm with four components), $2^{4}=16$ possible operating sequences should be counted. However, only the three sequences [1100], [0110], [0011] are valid and taken into account, which corresponds to respective voltages $U_{c}, 0,-U_{c}$. The rest of the combinations are irrelevant, otherwise they would cause practically short -circuit across the source Figure 15 [14, 15].

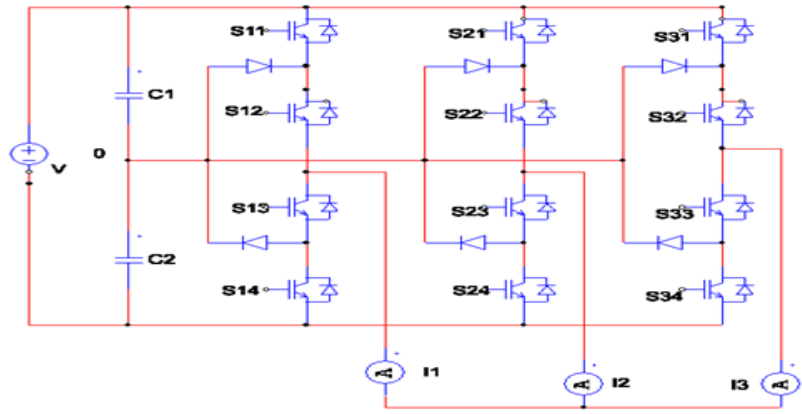

Figure 14. Structure of the NPC three-phase inverter

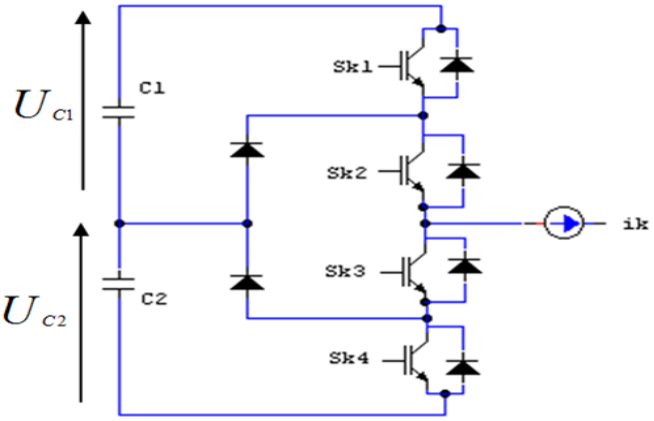

Figure 15. Inverter arm with three levels

\subsubsection{Control complementary for the inverter with three levels}

For a three-phase inverter with three levels in controllable mode, and to avoid short circuit of the voltage sources by conduction of several switches, the following complementary command is defined

$$
\left\{\begin{array}{l}
S_{k 1}=\overline{S_{k 4}} \\
S_{k 2}=\overline{S_{k 2}}
\end{array}\right.
$$

a) Connection function

We define the connection functions of half arm $F_{k 1}^{b}, F_{k 0}^{b}$ as:

$$
\left\{\begin{array}{l}
F_{k 1}^{b}=F_{K 1} F_{k 2} \\
F_{k 0}^{b}=F_{K 3} F_{k 4}
\end{array}\right.
$$

with $\mathrm{k}$ is the number of the $\operatorname{arm} \mathrm{k}=1,2,3$; and denotes by 1: the half-upper arm, 0: the half-arm low.

b) Modeling at instantaneous values

The potentials of the nodes A, B, C of the three-phase three-level inverter, by relative to the point $\mathrm{M}$ of the input voltage source are given by the system next, with $\mathrm{U}_{\mathrm{c} 1}=\mathrm{U}_{\mathrm{c} 2}=\mathrm{U}_{\mathrm{c}}$ :

$$
\left\{\begin{array}{l}
V_{a m}=F_{11} F_{12} U_{c 1}-F_{13} F_{14} U_{c 2}=\left(F_{11} F_{12}-F_{13} F_{14}\right) U_{c} \\
V_{b m}=F_{21} F_{22} U_{c 1}-F_{23} F_{24} U_{c 2}=\left(F_{21} F_{22}-F_{23} F_{24}\right) U_{c} \\
V_{c m}=F_{31} F_{32} U_{c 1}-F_{33} F_{34} U_{c 2}=\left(F_{31} F_{32}-F_{33} F_{34}\right) U_{c}
\end{array}\right.
$$


the compound tensions are given by:

$$
\begin{aligned}
& U_{a b}=V_{a m}-V_{b m}=\left(F_{11} F_{12}-F_{21} F_{22}\right) U_{c 1}-\left(F_{13} F_{14}-F_{23} F_{24}\right) U_{c 2} \\
& U_{b c}=V_{b m}-V_{c m}=\left(F_{21} F_{22}-F_{31} F_{32}\right) U_{c 1}-\left(F_{23} F_{24}-F_{33} F_{34}\right) U_{c 2} \\
& U_{c a}=V_{c m}-V_{a m}=\left(F_{31} F_{32}-F_{11} F_{12}\right) U_{c 1}-\left(F_{33} F_{34}-F_{13} F_{14}\right) U_{c 2}
\end{aligned}
$$

simple voltages are given as follows

$$
\left[\begin{array}{l}
V_{a} \\
V_{b} \\
V_{c}
\end{array}\right]=\frac{U_{C}}{3}\left[\begin{array}{ccc}
2 & -1 & -1 \\
-1 & 2 & -1 \\
-1 & -1 & 2
\end{array}\right]\left[\begin{array}{l}
F_{11}^{b}-F_{10}^{b} \\
F_{21}^{b}-F_{20}^{b} \\
F_{31}^{b}-F_{30}^{b}
\end{array}\right]
$$

\subsection{Simulations and results}

We treated first single phase inverter powered inductive load after we examined two most recommended known structures "voltage inverter with two levels and three structure levels NPC" controlled by two control techniques SPWM, THIRPWM which will be used to inject electrical energy from a PV source to the permanent magnet synchronous machine. This topology makes it possible to generate the most sinusoidal voltage possible and to improve the harmonic ratethanks to the high number of voltage levels offered by the structure of these multilevel converters.

We realized this work under environment MATLAB/SIMULINK for $\mathrm{m}_{\mathrm{f}}=333.33$ a fundamental frequency $\mathrm{f}_{\mathrm{r}}=60 \mathrm{~Hz}$ and $\mathrm{f}_{\mathrm{p}}=20 \mathrm{khz}, \mathrm{Uc}=200 \mathrm{~V}$. The test is characterized by a vacuum start, then a change of the resisting torque performed at the instant $\mathrm{t}=0.55 \mathrm{~s}$ during simulation. After the model validation shown in Figure 12 under Matlab-Simulink, we reported the results of simulations. In Figure 16 shows that the simple voltage $\mathrm{V}_{\mathrm{an}}$ takes two levels. The harmonic spectrum shows that there are two kinds of families: families of peer indices and odd indices. We can also see that voltage harmonics are grouped into families centered on the odd multiple switching frequencies of the fundamental frequency with a non-zero DC component. We observe that the compound voltage takes two levels $(0, \mathrm{Vc}=200 \mathrm{v})$. Then, we simulated the mathematical model of the three-level inverter controlled by the two-carrier PWM technique shows in the Figure 17, we note that the compound voltage takes three levels namely: $\mathrm{VC}, 0,-\mathrm{VC}$ hence the denomination inverter three levels. The harmonic spectrum of the compound voltage of Figure 17 shows that the even multiple harmonic frequencies of the fundamental frequency result in low amplitude only the odd multiple frequencies of the fundamental frequency are retained. The THIRPWM control in the two inverter structures (two levels and three levels) is shown in Figures 18, 19. Injection of harmonic of order three in the reference makes it possible to increase the zone of linearity of the fundamental one.
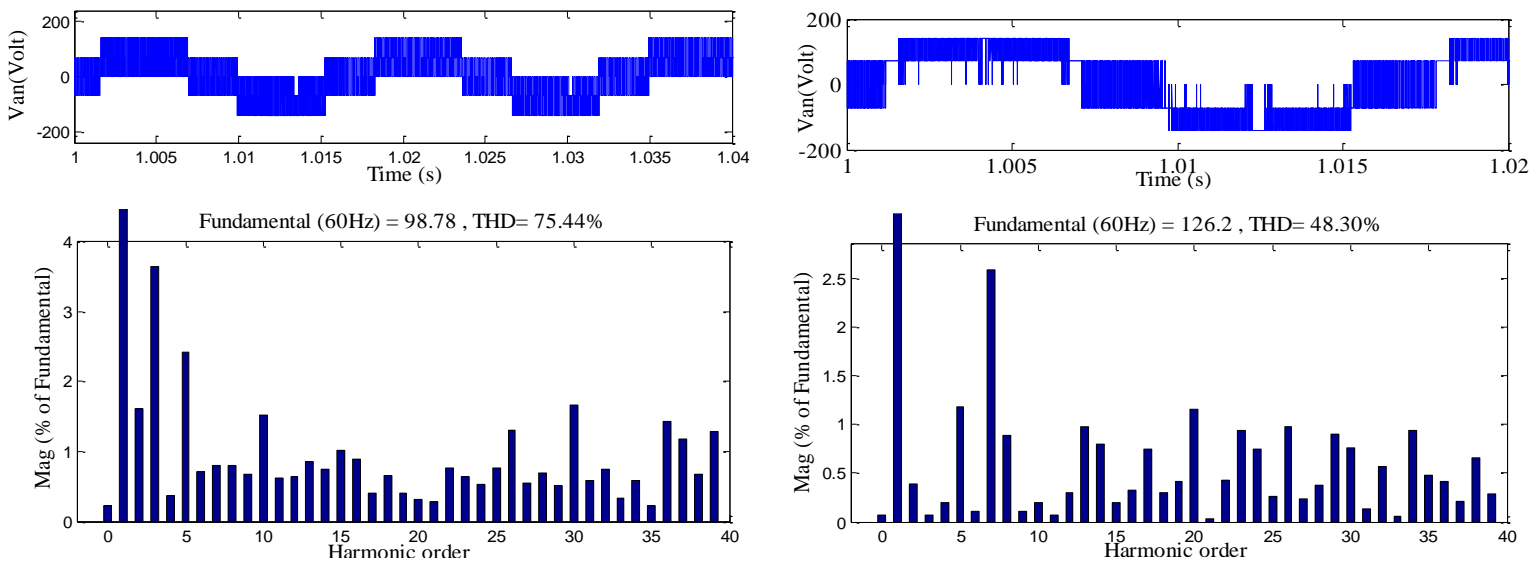

Figure 16. Simple voltage and its harmonic spectrum, $\mathrm{m}_{\mathrm{f}}=333.33, \mathrm{IM}=0.85, \mathrm{THD}=75.44 \%$, fundamental $=98.786$ volts for two-level inverter controlled by SPWM

Figure 17. Simple voltage and its harmonic spectrum, $\mathrm{m}_{\mathrm{f}}=333.33, \mathrm{IM}=1.15, \mathrm{THD}=48.30 \%$, fundamental $=126.2$ volts for two-level inverter controlled by THIPWM 

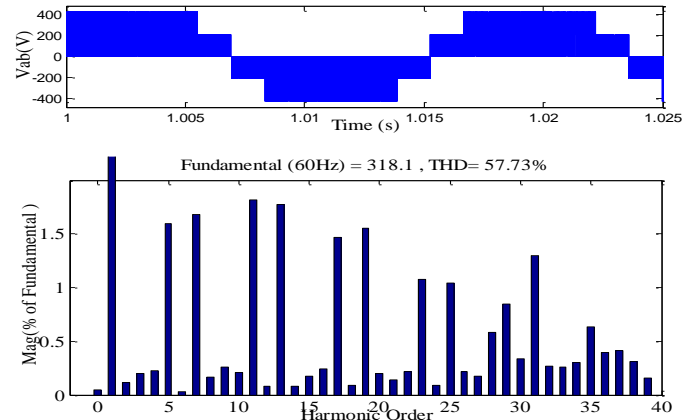

Figure 18. Compound voltage and its harmonic spectrum, $\mathrm{m}_{\mathrm{f}}=333.33, \mathrm{IM}=0.85, \mathrm{THD}=57.73 \%$, fundamental $=318.1$ volts for three-level inverter controlled bySPWM
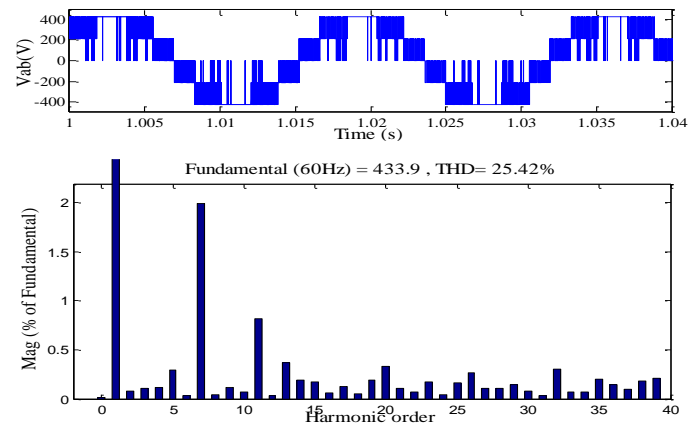

Figure 19. Compound voltage and its harmonic spectrum, $\mathrm{m}_{\mathrm{f}}=333.33, \mathrm{IM}=1.15, \mathrm{THD}=25.42 \%$, fundamental $=433.9 .1$ volts for three-level inverter controlled by THIPWM

We have reported the trend of three-phase currents of the two structures in Figures $20(a, b)$. Note that the current of the three-level structure has weak oscillations compared to the two-level structure. This is due to the number of sequences and the numbers of simple voltage levels that are more important in the three-level structure than in the two-level structure. We reported the rotational speed variations corresponding to the two control structures in Figures $21(\mathrm{a}, \mathrm{b})$. The behavior of the speed is practically identical in both cases. The electromagnetic torque of the two structures is shown in Figures $22(\mathrm{a}, \mathrm{b})$. There is a large band of strong oscillations in the electromagnetic torque in the two-level structure. These results in a high harmonic rate, while the three-level structure provides an improvement in the response of the electromagnetic torque Figure 22b.

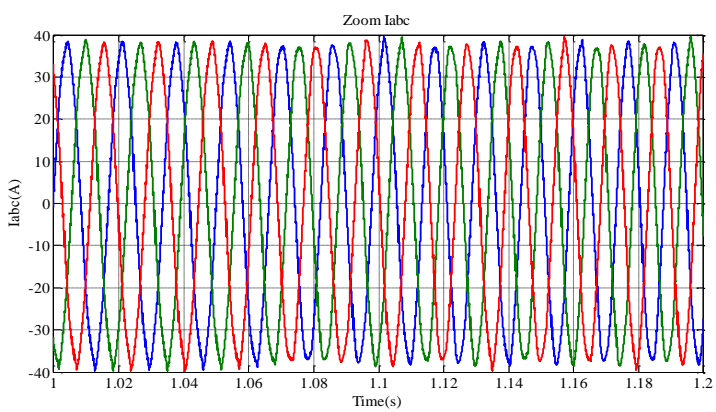

(a)

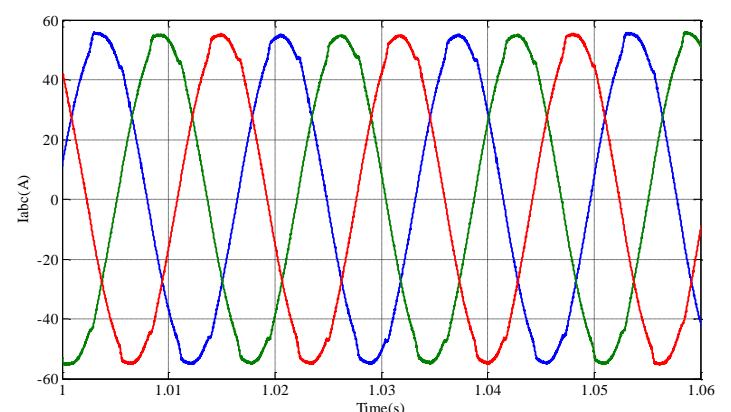

(b)

Figure 20. (a) Three phase motor current for two level inverters, (b) three level inverters

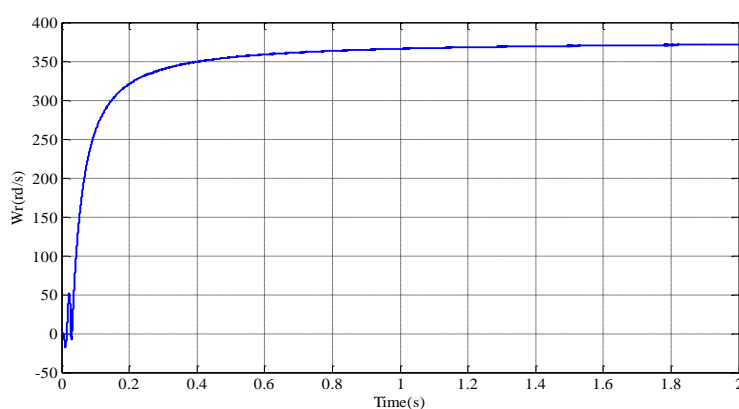

(a)

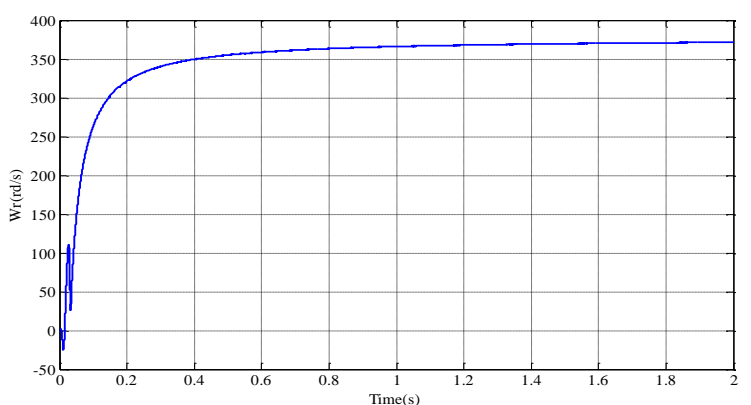

(b)

Figure 21. (a) Rotation speed of motor for the two- level inverter, (b) three level 


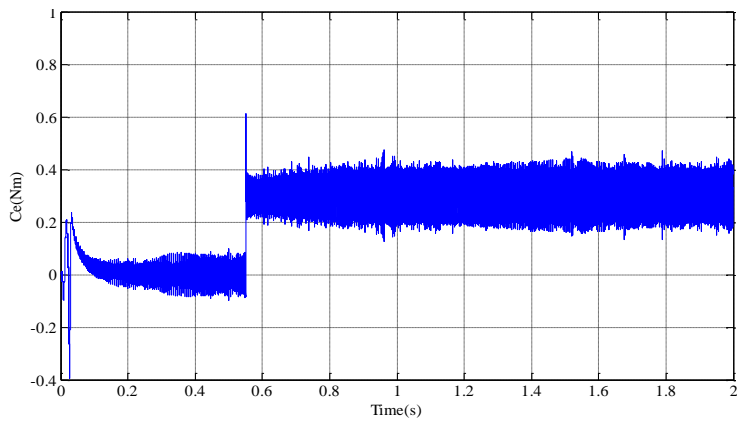

(a)

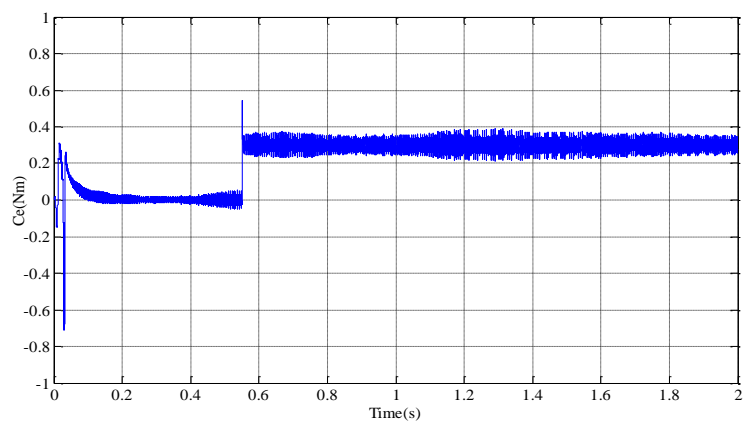

(b)

Figure 22. (a) Electromagnetictorque for the two-level inverter, (b) three level inverters

\section{CONCLUSION}

A comparative study of simulation results between the performance of the three-level inverter and the two-level inverter controlled by PWM and THIPWM showed that the three-level structure provides a clear improvement in DC-to-AC conversion. The choice of this command allowed us to optimize the operation by eliminating the maximum of harmonic of low rank, which entails a notable reduction of the oscillations of the couple and the speed of rotation. In this work, Simulink models for all two techniques (SPWM, THIPWM) have been developed and tested in the MATLAB/Simulink environment; their simulation results are compared and analyzed by plotting the output harmonic spectra of various output voltages, and computing their total harmonic distortion (THD). THIPWM have a superior performance compared to SPWM.The SPWM technique is very popular for industrial converters. It is the easiest modulation scheme to understand and implement. This technique can be used in single-phase and three-phase inverters. The THIPWM technique operates by adding a third harmonic component to the sinusoidal modulating wave. It is possible to increase the fundamental by about $15.5 \%$ and, hence, allow a better utilization of the DC power supply. From the shape of the line-to-line voltages, the resulting flat-topped waveforms allow over-modulation with respect to the original SPWM technique. In the case of the threelevel inverter, the output voltages have a much lower harmonics ratio than those generated by the two-level inverter. The harmonic spectrum of the output voltages shows that harmonics of odd and even ranks exist, but the odd harmonics are very small in amplitude in the three-level inverter. This implies a low cost for the filter that must be placed at the output. The THD is very low for the three-level structure compared to that generated by the two-level inverter.

\section{ACKNOWLEDGEMENTS}

The authors would like express their gratitude to University USTO, Algeria and Laboratory for Analysis and Application of Radiation (LAAR), Department of Applied Physics, Faculty of Physics, for their support on this project

\section{REFERENCES}

[1] V. Birunda Marya, I. William Christopher and G.Themozhi, "3 switch single phase inverter for PV system," Energy Procedia, vol. 117, pp. 674-681, 2017.

[2] Wahyu Mulyo, Afarulrazi Abu Bakar and Suhaila Alias, "Modeling of single phase 7-level Cascaded H- Bridge Multilevel Inveter," International Journal of Engineering and Technology, vol. 7, pp. 327-330, 2018.

[3] Usha Sharma and Vikramaditya Dave, "Matlab/simulink model of two-stage, grid connected 50kw solar system," International Journal of Research and Analytical Reviews, vol. 5, no. 3, pp. 596-601, Jul. 2018.

[4] Phuong Hue Tran, "Matlab/simulink implementation and analysis of three pulse-width-modulation (Pwm) techniques," Master of Science in Electrical Engineering Boise State University, May 2012.

[5] A. W. Leedy and R. M. Nelms, "Harmonic Analysis of a Space Vector PWM Inverter Using the Method of Multiple Pulses," 2006 IEEE International Symposium on Industrial Electronics, Montreal, QC, Canada, 2006, pp. 11821187, doi: 10.1109/ISIE.2006.295805.

[6] Abdelkader Bouarfa," Méthodes de commande par allocation de convertisseurs statiques polyphasés, multi-niveaux : de la modélisation à la mise en oeuvre temps-réel," Doctorat De L'université De Toulouse, Nov. 2017.

[7] J. A. Houldsworth and D. A. Grant, "The Use of Harmonic Distortion to Increase the Output Voltage of a ThreePhase PWM Inverter," in IEEE Transactions on Industry Applications, vol. IA-20, no. 5, pp. 1224-1228, Sept. 1984, doi: 10.1109/TIA.1984.4504587. 
[8] P. Udakhe, D. Atkar, S. Chiriki and V. B. Borghate, "Comparison of different types of SPWM techniques for three phase seven level cascaded H-Bridge inverter," 2016 IEEE 1st International Conference on Power Electronics, Intelligent Control and Energy Systems (ICPEICES), Delhi, India, 2016, pp. 1-5, doi: 10.1109/ICPEICES.2016.7853286.

[9] G Prakash, C Subramani, K Dhineshkumar and P Rayavel, “Analysis of Extended Z-source Inverter for Photovoltaic System," Journal of Physics: Conf. Series, Jan. 2018.

[10] P. Suresh, LokeshAnjaneyaPothana, Manoj VarmaPenmetsa, Shanmukha TejasSunkavalli, "Speed Control of Induction Motorusing SPWM BasedMultilevelInverter and ParallelConverters," International Journal of Recent Technology and Engineering (IJRTE), vol. 8, no. 2S11, Sep. 2019.

[11] Omar Mohammed Benaissa, et al., "Modeling and Simulation of grid connected PV generation system using Matlab/Simulink," International Journal of Power Electronics and Drive System (IJPEDS), vol. 8, no. 1, pp. 392401, Mar. 2017.

[12] Ali Farzan Moghaddam and Alex Van den Bossche, "Direct usage of photovoltaic solar panels to supply a Freezer motorwith variable DC input voltage," Electronics, vol. 9, no. 167, 2020.

[13] P. Suresh, Lokesh Anjaneya Pothana, Manoj Varma Penmetsa, Shanmukha Tejas Sunkavalli, "Speed Control of Induction Motor using SPWM Based Multilevel Inverter and Parallel Converters,"International Journal of Recent Technology and Engineering (IJRTE), vol. 8, no. 2S11, Sep. 2019.

[14] R. Palanisamy, et al., "Multicarrier-SPWM Based Novel 7-Level Inverter Topology with Photovoltaic System," International Journal of Power Electronics and Drive System (IJPEDS), vol. 8, no. 2, pp. 826-834, Jun. 2017.

[15] Dr. R. Nagarajan, et al., "Implementation of SPWM echnique for inverter," International Journal of Advanced Research in Biology, Engineering, Science and Technology (IJARBEST), vol. 2, no. 9, Sep. 2016.

\section{BIOGRAPHIES OF AUTHORS}

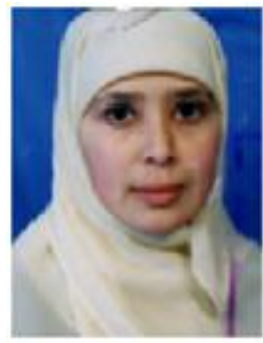

Falil Fatima hold a degree in Electrotechnical magister in 2009, currently She is PhD student in physics, I do some research on PV systems at the LAAR laboratory, department Physics in University Mohamed Boudief USTO in Algeria.

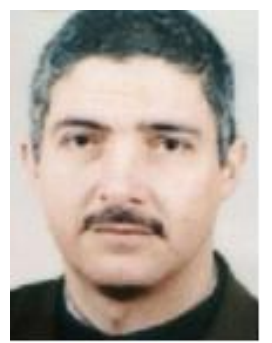

Benabadji Noureddine: was a teacher at the Intitute of Telecommunications - Oran (I.T.O) from 1984 to 1999, by following courses: electricity, tests \& measurements, electronic components, electronic circuits, logic circuits, computer hardware, microprocessors, assembly programming (8086), algorithms and programming in C+. Now, He is teacher/researcher at the University of Sciences \& Technology - Oran (U.S.T.O). He teach C.A.D (with AutoCAD) and doing R \& D in the laboratory LAAR (Laboratory of Analysis \& Applications of Radiations). His research team has designed a local station in order to receive images from polar and geostationnay satellites like NOAA and METEOSAT. 